\title{
El maestro sabio o las treinta mil leyes de las cuatro estaciones (primera parte)
}

\author{
José Luís Turabián Fernández ${ }^{a}$, Benjamín Pérez Franco ${ }^{b}$
}

\begin{abstract}
Médico de Familia. Tutor de residentes. Centro de salud Polígono Industrial. Toledo. España.

${ }^{\mathrm{b}}$ Médico de Familia. Tutor de residentes. Centro de salud La Estación. Talavera de la Reina. Toledo. España.
\end{abstract}

\begin{abstract}
RESUMEN
Con esta primera entrega iniciamos la publicación de una serie de cuatro artículos muy especiales, sobre la historia del maestro sabio, Gin y Seng, y su aprendiz de nombre cambiante. En una clara alegoría a la formación de los médicos internos residentes, los autores nos van describiendo las etapas por las que pasan los residentes, desde sus inicios titubeantes (primavera) hasta su actuación independiente (invierno), y nos dan las claves de lo que debe ser la labor de tutorización, desarrollando un completo curso de formación para tutores de residentes.

Revista Clínica de Medicina de Familia quiere así hacer un pequeño hueco en sus páginas para una de las labores fundamentales de muchos de nuestros lectores, que tienen en sus manos la responsabilidad de formar a los futuros especialistas.
\end{abstract}

Palabras clave: Educación Médica. Tutorización. Docencia. Médico interno residente.

\section{ABSTRACT}

The wise master or the thirty thousand laws of the four seasons (first part).

In this first issue, we begin the publication of a series of four very special articles about the story of the wise master Gin y Seng, and his apprentice with a changing name. In a clear allegory of the training of resident medical interns, the authors set about describing the stages which the residents go through, from their hesitant beginnings (spring) to their independent actions (winter), and they give us key insight into what the labour of tutoring should be, developing a complete training course for tutors of residents. Revista Clínica de Medicina de Familia (Medical Journal of Family Medicine) thus wishes to create a small space in its pages for one of the the fundamental jobs of many of our readers, in whose hands lies the responsibility to train future specialists.

Key words: Medical education. Tutoring. Teaching. Resident medical intern.

\section{Capítulo 1. La Ley de las Cuatro Estaciones del maestro sabio.}

-¡Eureka! -gritó con voz alborozada el Maestro Gin y Seng, mientras miraba por la ventana cómo caía la tarde y los pájaros cantaban encaramados en los nuevos tallos del viejo olmo del jardín-. ¡He descubierto la 'Ley de las Cuatro Estaciones'! Pareciera como si la vida fuese un eterno renacer... nace y muere el día, pero vuelve a nacer. Nace y muere el año, pero vuelve a nacer. Y así, los días, los años y sus estaciones se suceden.

Como puede ya apreciarse, el Maestro Gin y Seng era un individuo inspirado y entrenado en entender el mundo. Esta capacidad mental que ha cultivado, y cuyos impulsos y pasadizos domina, le sirve de técnica de profunda revisión personal y como camino para recibir verdades referidas al mundo exterior, que él vive como revelaciones, y que suele calificar como leyes.

$<<$ Quizá sea uno de los secretos más anunciados de la Historia, pero no por conocido deja de ser tema para la ciencia -meditó el Maestro Gin y Seng-. La naturaleza cíclica de la vida y de la enseñanza. Tal como avanzan las estaciones, se producen distintos ciclos que facilitan ciertas prácticas educativas. Mientras nuestra vida transcurre mecánicamente, giramos en la Rueda sin cesar, momento a momento y vida tras vida. En cada momento y ante cada situación podemos ir más allá de los límites de nuestro condicionamiento habitual y elegir una conducta consciente >>. 
Y escribió en la pequeña pizarra de su cuarto: $L a$ armonía con el momento es el elemento clave. Mientras estamos parados, el río del tiempo sigue fluyendo incesantemente.

Pero, conozcamos un poco más de este excepcional docente. El Maestro Gin y Seng también le llamaban cariñosamente "Sabelotodo" y "El Aprendizaje Victorioso" sus colegas- se graduó por la Universidad de Magia de Persia, y por la Universidad de Merlín, Canadá, con el título de Maestro, y trabajó unos años como editor de la prestigiosa revista Anales de Neo-Hechicería Docente, y como consultor del American Ethnobotany Council Institute, y ha vivido los últimos 20 años en Empiria, ejerciendo como maestro en el Centro de Hechicería Docente de esa localidad, estando siempre interesado por la investigación tanto en la Hechicería Docente, como en la referida a la formación de jóvenes maestros.

Como Hechicero Docente y como Científico, una meta inmediata que ha tenido siempre, ha sido el descubrimiento de nuevos hechos sobre la vida, en la esperanza de que tales conocimientos, en conjunción con los principios de las ciencias pedagógicas y sociales, pero también con los de las matemáticas, física, química, y biología, pudieran establecer nuevas generalizaciones y un conocimiento más completo del fenómeno de la vida, la docencia y el aprendizaje.

Pero sus ideales humanísticos, más que el conocimiento científico, fueron la razón principal de su actividad. El Maestro Gin y Seng siempre defendió que la acumulación de conocimiento científico debía estar subordinada a la producción de personas integrales que desarrollen todas sus potencialidades y logren conocerse a sí mismos.

Durante los años de trabajo en la Hechicería Docente creció su convicción de que esta tarea necesitaba urgentemente una reflexión y una redefinición de sus métodos y objetivos. Fruto de esta dedicación es el texto que se publica a continuación, traducido del idioma nativo del maestro. Con esta visión en su trabajo diario, el Maestro Gin y Seng ha logrado "descubrir" un cierto número de Leyes Docentes Científicas de la Formación de Aprendices que han revolucionado el mundo educativo. Son las leyes que gobiernan el universo de la formación del aprendiz; son inalterables y válidas por sí mismas. Existen desde un tiempo sin comienzo.

Para el Maestro Gin y Seng, el corazón de la práctica de la enseñanza a aprendices es la meditación, tanto la reflexiva como la contemplativa. El propósito de la meditación es pacificar y calmar la mente. Él sabe que nos cuesta mucho controlar la mente. Al igual que un globo suelto en el aire se zarandea de un lado a otro al capricho del viento, nuestra mente se tambalea inestable a merced de las circunstancias externas, en opinión del Maestro.
Cuando el Maestro Gin y Seng encuentra un lugar tranquilo donde poder meditar y se sienta en una posición cómoda, manteniendo sus ojos entreabiertos y respirando de forma natural, su mente se vuelve lúcida y espaciosa y se siente restablecido. Como cuando el mar está encrespado, el sedimento del fondo se agita y el agua se enturbia; pero cuando el viento cesa, el lodo se deposita en el fondo poco a poco y el agua se vuelve transparente... -piensa el Maestro Gin y Seng.

- ¡Caramba, la 'Ley de la Marea Baja'! -dijo el Maestro Gin y Seng, saliendo de su meditación-. Cuando la marea está baja, todo se ve muy diferente a cuando la marea está alta. Puedes coger crustáceos y conchas..., sin tener que sumergirte, sin bucear..., sólo caminando por la arena húmeda. ¡Se ven los tesoros! Ese cofre lleno de tesoros del galeón que naufragó hace siglos..., iqueda a simple vista! ¡Sin esforzarnos! La marea baja deja al descubierto especies vivas, y lodos, piedras..., pero también es posible encontrar bolsas de basura, latas de refrescos, maquinaria diversa... Pueden verse paisajes reveladores de conflictos morales y ecológicos... Muchas playas quedan al descubierto y muchos barcos varados en ellas. En casi todas las playas se encuentran algas arrastradas allí por las olas, pero las algas marinas vivas sólo se ven en los litorales rocosos durante la marea baja. Cuando baja la marea, decenas de depresiones y grietas quedan a la vista. La mayoría de ellas quedarán inundadas de agua, lo que variará dependiendo de sus dimensiones. Los organismos que habitan estas zonas se agrupan en bandas horizontales o se mantienen en los charcos formados al bajar la marea, todo depende de su adaptación a los cambios de humedad, salinidad, temperatura o resistencia al oleaje. Allí habrá crustáceos. También encontraremos lapas, así como algún molusco que se alimenta de esos crustáceos. Encontramos algas que cubren las rocas, y con ellas una rica fauna compuesta por cangrejos, gusanos, ... -recita en voz alta el Maestro, como si fuera un mantra, como si se estuviera escuchando un sonido interno sutil que siempre ha habitado en su sistema nervioso.

En esos momentos de meditación el Maestro Gin y Seng suele encontrar, no sólo leyes para la formación de los aprendices, sino consejos o normas sobre los que reflexionar los propios maestros.

Cuando haya marea baja, levántate un día de madrugada y ve hasta la orilla de la playa, donde la arena está húmeda. Allí hay infinidad de conchas..., ¡será una experiencia muy bonita! -escribió en la pequeña pizarra de su cuarto.

En esos momentos, el Maestro Gin y Seng se imagina a veces siendo de verdad "El Aprendizaje Victorioso", un personaje de cómic -como el Guerrero del Antifaz- que cabalga ayudando a 
estudiantes y es como fuente de beneficios y felicidad de sus aprendices.

Los capítulos de esta historia -y esto ya es una de las famosas Leyes descubiertas por el Maestroconforman cuatro estaciones: primavera, verano, otoño e invierno, la 'Ley de las Cuatro Estaciones'. Como el Maestro Gin y Seng dice: "Hay climas exteriores pero también interiores. Tenemos que abrir nuestros sentidos a la Naturaleza, pues es un espejo de nuestra propia naturaleza. Como las estaciones cambian, los aprendices cambian: niño, joven, adulto y anciano. Hacen un viaje de aprendizaje con el maestro. Cada estación tiene su tesoro. Cómo ayudar a que el aprendiz encuentre ese tesoro es la tarea del maestro".

Aún podemos oír su risa de angelote malo. Aún podemos verlo en la reducida estancia de su aposento, amueblada con una mesa desvencijada y cuatro sillas. En una esquina, un muestrario variado y confuso de la Docencia Basada en la Evidencia, velas encendidas, pequeños montones de revistas de Hechicería Docente y de artículos sacados de ellas, que él llama "un montón de palabras". Todo en un magnífico desorden digno del espíritu de Empiria.

El Maestro Gin y Seng no es un hombre ni mucho menos tan decrépito como era de esperar por su edad, de aspecto herbáceo, ligeramente aromático, con una cierta forma que asemejaba una raíz, de color levemente moreno, de cara redonda y piel curtida, y con dos ojos como dos farolillos de verbena: intensos, cálidos y tan llenos de vida que es difícil compaginarlos con ese cuerpo ya magullado por los años. Su sonrisa al hablar se va haciendo amplia y pícara y su voz anima a expresarse a quien le escucha, mientras sus manos, como raíces, revolotean inquietas por el aire. Se considera Guardián del Bosque, testigo del entorno, conexión con el ser interior. Su semblante se comporta como un espejo, reflejando el estado de ánimo de quien lo observa.

Para el Maestro Gin y Seng, ayudar a los aprendices es un camino para el conocimiento del Cosmos y el autoconocimiento. Y para lanzarnos a la búsqueda del autodescubrimiento necesitamos energía que nos dé esa pasión con la cual investigar y hacernos acreedores de esos misterios que están en el Universo. Para conseguirlo, el Maestro necesita ser despiadado, astuto, paciente y dulce. Ser despiadado no significa aspereza, la astucia no significa crueldad, ser paciente no significa negligencia, y ser dulce no significa estupidez. Se le atribuyen casi todas las cualidades, algunas contradictorias, como que es sedante y estimulante de los alumnos.

El Maestro Gin y Seng tiene una regla cuyos preceptos le guían en todo momento. El primer precepto de la regla es que todo lo que nos rodea es un misterio insondable. El segundo precepto de la regla es que debemos tratar de descifrar esos misterios, pero sin tener la menor esperanza de lograrlo. El tercer precepto es que un profesional Hechicero Docente, debe ser consciente del insondable misterio que le rodea y de su deber de tratar de descifrarlo, considerándose él mismo uno de ellos. Por consiguiente, para un Hechicero Docente el misterio de "Ser" no tiene fin, aunque "Ser" signifique ser una piedra o una hormiga o uno mismo. Esa es la humildad del Hechicero Docente. Uno es igual a todo. El Hechicero Docente es un especialista. El desconocimiento de su especialidad ha hecho que se le nombre con palabras como brujo, curandero o sanador, términos ambiguos que no son siempre sinónimos de su especialidad, pero qué le vamos a hacer...

Como dice el propio Maestro Gin y Seng, aunque no estoy seguro si refiriéndose a su especialidad o a la 'Ley de las Cuatro Estaciones': ¡C'est la vie!

\section{Capítulo 2. La formación del aprendiz: la primavera.}

Amanece. El Maestro Gin y Seng observa con su habitual brillo en los ojos, la salida del sol, mientras espera la llegada de su nuevo aprendiz. Después del frío invierno, la naturaleza parece despertar y renacer en la primavera. Ahora, a medida que la tierra se calienta, las semillas de las plantas empiezan a brotar. Los arces y robles que durante el invierno estaban desnudos y sin hojas, empiezan a enviar la savia hacia sus ramas, para que puedan brotar y crecer nuevas hojas...

-iAh, el tesoro de la primavera! -suspira el Maestro-. Los sentidos del aprendiz despertarán ante la inmensidad que le rodea. Allí donde pose su atención habrá un nuevo destello. ¡Hay tanto por descubrir! El aprendiz deberá sacudirse las rutinas y lanzarse ligero a la aventura del descubrimiento -medita sentado en la silla de su despacho.

-El tesoro de la primavera es vivir el presente, entregarse a cada instante con decisión y confianza a una exploración de las fronteras, empezando de cero -dice dulcemente, en voz baja, como para sí mismo-. Sin lamentos ni excesos de preocupaciones, disfrutando de la amplitud de lo que se ofrece sin asustarse por lo desconocido. Transformando los problemas en retos y disfrutando en superarlos, reconociéndose un poco más amplio con cada experiencia.

$Y$ escribe en un papel que luego coloca en un lugar bien visible en la pared:

¿Cómo encontrar el tesoro de la primavera? Aplicando las leyes por mí descubiertas, que son:

\section{La Ley de las Individualidades}




\section{La Ley del Precalentamiento}

Las Leyes de los Cincuenta Tonos de Azul y de la Exposición o Familiaridad

La Ley de Parkinson

La Ley del Surf

La Ley Spock

La ley del mar de Tiberiades y del mar Muerto

\section{Capítulo 3. La Ley de las Individualidades.}

El aprendiz del Maestro Gin y Seng era Tallo-Verde, un pequeño retoño verde que se impulsaba hacia fuera del suelo para convertirse en una planta. Así llegaba el nuevo aprendiz al Centro de Hechicería Docente. El amable lector no tiene idea de lo que representa un aprendiz nuevo en una clase de Hechicería Docente. Es como un 'elefante en una casa de cristal'. No sabe en dónde se guardan las cosas, se tropieza con todo, se le caen las drogas psicoactivas y los alcaloides, tarda treinta minutos en entender un concepto que debería tomarle diez, se desespera fácilmente, y cuando llega el momento de realizar una reflexión importante o un experimento valioso..., tiene que irse antes, o no viene ese día, y deja todo en manos de los demás.

Pero al día siguiente regresa con bríos renovados, y poco a poco va ganando su sitio y adquiriendo destreza, hasta que un día se hace su primera pregunta personal. Éste es el día que debe celebrarse como el de su nacimiento a la comunidad científica de la Hechicería Docente; hay que estimular al estudiante a que medite sobre su idea, la pula y le dé vueltas, la critique sin compasión y si al final todavía queda algo, que la ponga a prueba. $\mathrm{Y}$ hay que apoyarlo moralmente cuando, como ocurre con frecuencia, los resultados son un fracaso completo.

El joven Tallo-Verde no tenía nada en común con el Maestro Gin y Seng, salvo sus aspectos herbáceos. Este era originario de la China, mientras que aquélla era una planta perteneciente a la familia de las labiadas, que brotaba en primavera con tallos cuadrados, vellosos y de uno a dos palmos de altura; sus hojas estaban sostenidas por largos rabillos y eran de figura ovoide, enteras, o con dientes no muy pronunciados, y carecía de aroma. Se había criado en prados húmedos.

El joven Tallo-Verde y el Maestro se encontraron por primera vez cuando el coordinador del Consejo de Ancianos Docentes presentó un lunes a primera hora a los aprendices que se incorporaban al Centro de Hechicería Docente. Tallo-Verde no conocía a nadie en el Centro; la gente le pareció muy exclusivista, hablando en camarillas. Las conversaciones le sonaban a código.
$<<$ Aquí todos somos muy amigos y, si no eres uno de nosotros ahora, ya no lo serás nunca >> pensaba Tallo-Verde que querían decir.

El coordinador hizo una presentación de lo que suponía la llegada de los aprendices, y uno de los maestros contó unas frases muy largas de unos autores famosos, de las que Tallo-Verde solo recordó algo así como: "antorcha y guía de la Humanidad" y "el azar favorece a las mentes preparadas". La gente le vitoreó, él no entendió qué tenía de importante o divertido, y se puso a pensar en su casa.

-Hola -le dijo alguien a Tallo-Verde desde detrás de él que, sobresaltado, se volvió rápidamente-. Soy El Maestro Gin y Seng. El coordinador me ha dicho que eres mi aprendiz.

¡Oh, no! -pensó él-. ¡El de la frase de la antorcha, no! Pero logró devolver el saludo

-iHola!

El Maestro Gin y Seng le hizo las preguntas habituales sobre de dónde eres, qué tal... Quedaron para comenzar a trabajar juntos al día siguiente. Ese día, cuando llegó Tallo-Verde, el Maestro gritó alborozado...

- ¡Eureka! ¡He descubierto la 'Ley de las Individualidades'.

Tallo-Verde dio un salto del susto. Pero, el Maestro Gin y Seng, sin inmutarse por la verde palidez súbita de Tallo Verde, recitó en voz alta: "A igualdad de las ondas en que se mueven las diferentes partículas, cada hombre es un conjunto de vibraciones único, irrepetible, completamente diferente de los demás. Podríamos decir que tiene su propia música, y que ésta es tan distinta de unos a otros como el ADN. No buscar lo que unifica a los hombres, sino lo que les separa. Respeto a la individualidad y la diversidad. La referencia es el universo múltiple: cada persona es un conjunto de vibraciones único e irrepetible. La tarea de todo hombre consiste en iniciar el camino que le conducirá al centro de su ser. Liberarse de un hábito colectivo para resurgir con unos ropajes propios, que no han existido nunca ni existirán jamás. Nacer de nuevo. La vida es un ascenso sin límites y el tiempo no es ningún oprobio para el hombre, sino la posibilidad de una mayor perfección. El hombre se va despojando de todo aquello que no le pertenece estrictamente - generación, país, herencia familiar, superestructura ideológica- para emerger él mismo, tal y como todo hombre es, único e irrepetible. Se trata de una ardua tarea, llena de altibajos, avances y retrocesos, y a la que, generalmente, sólo se llega en la avanzada madurez" -concluyó con cara de satisfacción el Maestro Gin y Seng.

-O sea-reflexionó el Hechicero Docente en voz alta-, esta Ley sostiene que la misión de todo hombre y 
de toda mujer es alcanzar su individuación, es decir, llegar a ser, en el pleno sentido de la palabra, él o ella mismos. Toda individuación pasa por diferentes etapas. Una de las primeras es el encuentro con 'la sombra', la parte más oscura y siniestra de nosotros. Quien progresa en su individuación, debe integrar en su personalidad esa 'sombra', asumirla, pactar con ella.

Efectivamente, el Maestro Gin y Seng había descubierto la 'Ley de las Individualidades' al conocer el día anterior a su nuevo aprendiz. Y meditó: El maestro y el aprendiz son como dos joyas preciosas, cada una en su estilo, diamante $y$ esmeralda. Y lo escribió en la pequeña pizarra de su cuarto.

\section{Capítulo 4. La Ley del Precalentamiento.}

El Maestro Gin y Seng dedicó algunos ratos durante los primeros días que estaba el aprendiz, que era Hierba-Siempre-Verde-y-Espesa, a charlar sobre ella y sus deseos... El Maestro Gin y Seng se esforzaba en lograr un cierto tipo de relación genuina, real, entre Hierba-Siempre-Verde-yEspesa y él. Es decir, lograr estar conscientes de nuestros sentimientos y capaces de expresarlos con nuestras propias palabras y actitudes. Era una relación transparente por parte del Maestro, donde sus sentimientos reales eran evidentes.

$Y$ hablaban, yendo de un tema a otro.

-¿Qué sentimientos o emociones tienes ahora? ¿Puedes contarme el incidente o acontecimiento más difícil que hayas tenido en tu práctica en los últimos meses?, ¿cómo actuaste?... ¿Dónde te gustaría estar dentro de 5 años? ¿Estás trabajando para lograr esas metas? ¿Cuáles son tus puntos fuertes personales? ¿Conoces cuáles son las fuerzas negativas y positivas para lograr tus planes futuros?... ¿Cómo pasas el tiempo cuando no estás trabajando?... ¿Qué circunstancias o acontecimientos encuentras más estresantes? ¿A quién te diriges cuando buscas apoyo? ¿A quién ofreces apoyo?... ¿Cuál es tu estilo preferido de aprendizaje?... -preguntaba y escuchaba el Maestro Gin y Seng.

El Maestro quería comprender y aceptar a HierbaSiempre-Verde-y-Espesa, y quería hacerle ver que la consideraba una persona de valía y con derechos, independientemente de sus atributos actuales, condición, comportamiento, o sentimientos, sean buenos o malos. Esto significaba respeto y empatía sensible.

El Maestro Gin y Seng escuchaba y meditaba: $<<$ El individuo tiene en sí mismo la capacidad y la tendencia, latente o evidente de dirigirse hacia la maduración y hacer presentes las potencialidades, llegando a ser autónomo. Esta tendencia debe romper unas profundamente enraizadas defensas psicológicas. Un ambiente de seguridad y de valoración es indispensable para que ocurra el aprendizaje>>.

Y seguía meditando: <<Buscar las condiciones para proporcionar ayuda a otra persona para que se desarrolle. Mientras leas o escuches, no te esfuerces demasiado. Sé como la tierra. Cuando llega la lluvia, la tierra sólo tiene que abrirse a ella. Deja que la lluvia llegue y penetre hasta las semillas enterradas en el fondo de tu conciencia. Un maestro no puede dar la verdad. La verdad está ya en tu interior. Sólo necesitas abrir el cuerpo, la mente y el corazón para que sus enseñanzas penetren hasta tus propias semillas de comprensión e iluminación. Si dejas que las palabras penetren en ti, el suelo y las semillas harán el resto del trabajo>>.

Y anotó en su pizarra: La suave lluvia primaveral penetra en el suelo del alma. Una semilla enterrada durante muchos años en las profundidades de la tierra empieza a sonreír.

- ¿Te parece mal que perdamos tanto tiempo en esta especie de presentación, en vez de dedicarnos a la formación que es a lo que venimos aquí...? ¡Y con el poco tiempo de que disponemos !-preguntó el Maestro Gin y Seng a Hierba-Siempre-Verde-yEspesa.

-No..., esto..., me parece bien que hablemos... -contestó el aprendiz.

-Bueno..., a partir de la semana próxima comenzaremos la formación... ¿o crees que la hemos empezado ya? -preguntó el Maestro Gin y Seng.

-Me parece que hemos empezado mi formación hace bastante rato... -contestó sonriendo HierbaSiempre-Verde-y-Espesa.

-Abraham Lincoln, dijo: "Si tuviera nueve horas para talar un árbol, emplearía siete de ellas en afilar el hacha”. Es la 'Ley del Precalentamiento', también descubierta por mí, claro está. Ya sabes..., el precalentamiento debe ser siempre el primer paso en la preparación del cuerpo para que se adapte lentamente, sin sufrir presiones exageradas, a una serie de ejercicios cuya intensidad irá aumentando de forma gradual... ¡incluso al proponerse dar un paseo andando es conveniente un precalentamiento! -explicó el Maestro Gin y Seng.

\section{Capítulo 5. Las leyes de los Cincuenta Tonos de Azul y de la Exposición o Familiaridad.}

El aprendiz comenzaba a pasar sus primeros días de aprendizaje. ¡Ahora parecía más un JovenJilguero-Que-Canta-En-Primavera que un tallo verde o una hierba siempre verde y espesa! 
El despacho del Maestro Gin y Seng daba pocas pistas sobre su ocupante. Ya dijimos que estaba amueblado con una mesa desvencijada y cuatro sillas, y había pequeños montones de revistas de Hechicería Docente y de artículos sacados de ellas, por todos lados. Salvo por las velas encendidas, y ciertas semillas producidas por plantas recogidas en la selva, la habitación podría haber pertenecido a cualquiera.

-Joven-Jilguero-Que-Canta-En-Primavera -dijo el Maestro Gin y Seng-. Estoy entusiasmado de trabajar contigo. El coordinador del Consejo de Ancianos Docentes me ha dicho que eres un aprendiz estupendo.

Joven-Jilguero-Que-Canta-En-Primavera no sabía ni qué, ni cómo responder, pero el Maestro Gin y Seng continuó como si todavía no esperara una respuesta.

-Has estado un tiempo formándote antes en la escuela..., y me gustaría saber más cosas de ese aprendizaje. Además, quisiera que me digas cómo puedo ayudarte en tus primeros días aquí.

Joven-Jilguero-Que-Canta-En-Primavera

no

estaba seguro, pero le preguntó al Maestro Gin y Seng, interrumpiendo su gorjeo que sonaba a un allegro:

-¿A qué hora terminamos?

Era un buen comienzo, no había duda. El Maestro Gin y Seng, le dijo:

-He preparado una lista de las preguntas que hacen los aprendices nuevos, junto con las respuestas. $-Y$ le entregó un papel-. Sobre lo de terminar..., no lo sé seguro....

Joven-Jilguero-Que-Canta-En-Primavera empezaba a sentirse más cómodo con el Maestro Gin y Seng.

-No sé lo que pensarás del Centro de Hechicería Docente -siguió diciendo el Maestro-. Pero sí me acuerdo de cómo me sentía yo cuando llegué aquí. ¡Me parecía una secta de chamanes cerrada que no quería nuevos miembros! Tendemos a preferir cosas que ya hemos visto antes, simplemente porque nos son familiares. Recuerdo que me sentía absolutamente asustado y preguntándome si me había equivocado en mi decisión. Pero no me iba a dejar vencer, y así lo que hice fue simplemente empezar a mirar a las personas con cariño. ¿Y sabes qué? ¡Me funcionó! Descubría y descubría aspectos maravillosos de la personalidad de cada una.

-Son las 'Leyes de los Cincuenta Tonos de Azul' y de la 'Exposición o Familiaridad' -explicó orgulloso el Maestro Gin y Seng-. Los pintores que residen en Formentera e intentan pintar los azules y turquesas de su mar, dicen que cada mes descubren un nuevo tono de azul. Llevan localizados más de cincuenta tonos de azul. Y siguen descubriendo nuevas tonalidades en sus aguas... Cuando miras a una persona con cariño descubres y descubres tonos maravillosos de su personalidad, y cada poco descubres otro y otro y otro....

-¡Yo leí que un ordenador calculó unos cuatro millones de tonos azules! -corrigió Joven-JilgueroQue-Canta-En-Primavera.

-Bueno, bueno... -siguió el Maestro-. Por otra parte, tendemos a preferir cosas que ya hemos visto antes, simplemente porque nos son familiares. Los seres humanos somos criaturas de hábitos. Las preferencias pueden formarse en base a la familiaridad o la exposición únicamente. En los años 70 del siglo pasado se hicieron una serie de experimentos en donde se mostraban unas imágenes visuales en una pantalla tan rápidamente que los espectadores no eran conscientes de lo que se proyectaba. Luego proyectaban otras imágenes y pedían que eligieran las que preferían; los espectadores elegían aquéllas que habían visto en el pase rápido. Alguna pequeña parte de aquellas imágenes había sido procesada por su cerebro, incluso no siendo conscientes de ello. Los espectadores daban un amplio abanico de razones para elegir la imagen, pero la única cosa común entre las imágenes elegidas era que habían sido percibidas antes, incluso inconscientemente, o subliminalmente.

$<<$ Se podría decir que, para enseñar eficazmente, el maestro debe conocer las predilecciones, personalidad, tendencias habituales, habilidades, etc., del aprendiz -pensó el Maestro Gin y Seng-. Cada persona va haciendo su camino, va proponiendo sus propios derroteros, y es una persona única. La formación tiene que permitirle ir desplegándose en muchas facetas distintas $>>$.

Y escribió en su pizarra: La talla de las gemas, mostrando facetas, tiene por objeto resaltar más sus cualidades: color, brillo, transparencia, resplandores....

- Yo no conocía estas leyes, pero parecen interesantes -dijo Joven-Jilguero-Que-Canta-EnPrimavera. ¿Usted las descubrió?.

-Ejem..., efectivamente -contestó el Maestro con voz demasiado alta, y añadió, ahora con un hilillo de voz- ... pero quizás demasiado tarde.

\section{Capítulo 6. La Ley de Parkinson.}

El joven aprendiz, que ya no parecía un jilguero sino el rumor de una fuente, llevaba unas semanas en la clase. Era una clase dura. La lista de materias era muy larga, los horarios extenuantes, los trabajos difíciles. Tanto era así que el Maestro Gin y Seng no tenía tiempo ni para tomar un café o inhalar el humo de las hojas de alguna planta mágica. 
Joven-Rumor-De-Una-Fuente, le preguntó al Maestro Gin y Seng:

- ¿Siempre está toda la mañana ocupada?

-Efectivamente -contestó el Maestro.

- ¿Pero, a veces habrá menos deberes que hacer? -insistió el aprendiz.

-Cuando hay pocos deberes, también tenemos ocupada toda la mañana-contestó el Maestro Gin y Seng. Y al ver la cara de sorpresa de Joven-RumorDe-Una-Fuente, le explicó: es la 'Ley de Parkinson'. El trabajo se expande hasta llenar todo el tiempo disponible por completo. Aunque tengamos "poco" trabajo, seguimos sin tener tiempo para hacer lo que quisiéramos. Enseñar en el momento apropiado; cuando el aprendiz esté preparado para recibir las enseñanzas y entenderlas -pensó el Maestro Gin y Seng.

Y escribió en su pizarra: El momento justo es un elemento clave.

\section{Capítulo 7. La Ley del Surf.}

A las pocas semanas de estar en la clase, el aprendiz, que ahora parecía el susurro de las hojas verdes con el viento, preguntaba o comentaba al Maestro Gin y Seng, con cierta frecuencia.

-No sé nada sobre este concepto..., tengo que estudiarme esto otro..., es difícil entender este tema,....

Así que no le quedó más remedio al Maestro Gin y Seng que descubrir una Ley.

-¡Aja! -gritó. Tus comentarios me han hechodescubrir la 'Ley del Surf'. Y añadió, pensativo: aunque puede llamarse también la 'Ley de la Navegación', o bien, 'La Ley del Judo'.

Joven-Susurro-De-Las-Hojas-Verdes-Con-ElViento no se atrevió a decir nada, así que el Maestro Gin y Seng, le explicó:

-Sí, la 'Ley del Surf'. En tanto que no hay dos olas iguales, el mar se conduce de una manera bastante lógica y consistente. Pero lleva tiempo tener la capacidad para interpretar la superficie y predecir los próximos movimientos para poder "correr" olas sucesivamente. Desde el primer momento que se toca el agua no hay que luchar contra el mar, sino que hay que aprender a comprender y dirigir sus fuerzas para aprovecharlas con respeto. Lo más asombroso de todo, es que no sólo se sobrevive, sino que además se puede jugar en medio del tremendo poder de las olas y las corrientes. Este es uno de los goces básicos del surf. Además, da auto-confianza en un medio que por el poder que tiene normalmente asusta. Lo mismo pasa con un barco. Para capear el temporal a motor habrá que recibir las olas de amura en un ángulo de 15 ó 20 grados, intentando ante todo no atravesarse a la mar. Deberá ajustarse la potencia del motor a las revoluciones adecuadas que permitan gobernar el barco sin chocar contra las olas.

-Y ya sabes el principio básico del judo -continuó. Tomar ventaja de la fuerza del oponente, ser flexible y ceder. El judo es ese arte del camino suave. Una forma sencilla de vivir y entender las cosas de la vida haciéndolas más simples y efectivas. Cuando la nieve del invierno cae sobre los árboles y se acumula pesadamente, las ramas soportan ese peso hasta cierto límite. Más allá de esa capacidad las ramas se doblan elástica y plásticamente dejando caer la nieve al suelo para recuperar luego su posición original. En judo se aprovecha la fuerza y la velocidad del oponente para dejarlo pasar y doblegarlo. La fuerza del oponente se pierde y se le aplica una nueva fuerza pero en otra dirección con lo cual el oponente pierde su equilibrio y se toma control de él. Este es el principio económico de la máxima eficacia con el mínimo esfuerzo. No ir contra la fuerza del oponente, sino más bien vencerlo usando su fuerza. Así pues, JovenSusurro-De-Las-Hojas-Verdes-Con-El-Viento, debes saber dejarte llevar como en el surf. Debes convertir el presente en un acto de creatividad constante. Debes ser impulsivo, sí, pero cuidando de no derivar en ceguera o tozudez, y no cruzarte o enfrentarte a las olas. Debes seguir el principio de la suavidad.

El Maestro se puso a meditar: $<<$ Si un aprendiz recibe una enseñanza clara con desmotivación o una visión errónea, el aprendizaje se distorsiona. Es como poner un néctar excelente en un vaso con veneno. O como si el vaso estuviera roto; en esa situación no importa lo clara que sea el agua o lo excelente del néctar que pongas, que no será retenido $>>$.

Y escribió en su pizarra: Si ponemos agua clara en un vaso sucio, se vuelve turbia.

\section{Capítulo 8. La Ley Spock.}

El aprendiz, que parecía ahora un almendro florido blanco y rosa, llevaba varios días llegando tarde. Estaba junto al Maestro Gin y Seng recibiendo sus enseñanzas.

El Joven-Almendro-Florido-Blanco-y-Rosa, al que se le abría la boca mientras se desperezaba extendiendo sus ramas, dijo:

-¡Esto es aburridísimo!

-Ahora no tenemos tiempo para discutir eso, JovenAlmendro-Florido-Blanco-y-Rosa, lo hablaremos al terminar la clase -dijo el Maestro Gin y Seng, mirando tranquilamente y sin sonreír a su pupilo. El Maestro notó la emoción de aburrimiento, impaciencia, y quizás inseguridad y confusión del Joven Almendro Florido Blanco y Rosa. Y también notó sus propias emociones... de decepción, 
disgusto, frustración, hostilidad, irritación... Y en ese momento, se dio cuenta que estaba por descubrir otra importantísima Ley de la Naturaleza.

-¡Vaya! -gritó el Maestro Gin y Seng-. ¡Ya lo tengo! La 'Ley Spock'.

Joven-Almendro-Florido-Blanco-y-Rosa se acabó de despertar. Sus emociones probablemente eran ahora de excitación e interés...

- ¿Spock? -dijo.

-Sí, Spock, el alienígena de Star Trek, mitad humano mitad vulcano, era una criatura de aspecto humano -salvo por sus orejas y cejas-, pero que ocultaba una diferencia profunda que teóricamente le hacía superior a los humanos: no tenía emociones; en algún momento de su pasado, los vulcanos habían perdido los primitivos vestigios de sus orígenes animales, y habían logrado un grado aparentemente mayor de racionalidad, al despojarse de las emociones.

-Se supone que un ser sin emociones debería ser más inteligente de lo que somos los seres humanos -prosiguió-. Esta es la idea tradicional occidental, desde Platón: "las emociones son un obstáculo para la acción inteligente". Sin embargo, está la idea opuesta: las acciones inteligentes se producen como resultado de la conjunción armoniosa de la emoción y la razón. Los organismos sin emociones son menos racionales que los seres humanos. Saber cuándo seguir nuestros sentimientos y cuándo ignorarlos es lo que constituye la "inteligencia emocional". Las emociones son aliados, no enemigos de la razón. En base a esta idea, Spock podría ser realmente menos inteligente, en vez de más inteligente, que los humanos.

-Existe la idea de que los sentimientos son subjetivos y confusos y que por ello no deberían formar parte del pensamiento lógico y objetivo. Esto es totalmente absurdo. Al final son nuestros sentimientos los que dan valor al fruto de nuestro pensamiento -dijo el Maestro Gin y Seng.

- ¿Cuáles son tus sentimientos sobre este asunto? ¿Cuáles son los sentimientos de las otras personas implicadas? -preguntó el Maestro al Joven Almendro Florido Blanco y Rosa.

-Esto..., pues... -intentaba reflexionar en voz alta el aprendiz.

-Las emociones tienen mal cartel en la Hechicería Docente. Se enfatizan los peligros de la participación emocional, pero no de la ausencia de emociones. Se considera que la madurez emocional consiste en la ausencia de emociones (u olvidarlas y esperar que desaparezcan) más que poseer las habilidades necesarias para expresarlas apropiadamente. Se habla más de controlar emociones que de favorecerlas. Se dice que hay que ser "objetivo" y justo, y no subjetivo y tener emociones -concluyó el Maestro Gin y Seng.

-Mmmm... -dijo Joven-Almendro-Florido-Blancoy-Rosa-. En realidad, Spock siempre ha intentado ocultar sus emociones humanas para ganarse el respeto de su padre y congéneres vulcanianos, pero aun sin tener aparentemente emociones siempre ha sido un apasionado del ajedrez tridimensional.

$<<$ ¡Cuánta paciencia hay que tener! -pensó el Maestro Gin y Seng-. El Maestro debe tener 3 tipos de paciencia: paciencia para mantener su interés y entusiasmo en las largas sesiones de enseñanza; paciencia para afrontar las preguntas y comportamientos del aprendiz; y paciencia para responder con argumentos $>>$.

Y escribió en su pizarra: Ejercer la paciencia que brilla por sí misma.

\section{Capítulo 9. Ley del Mar de Tiberíades y del Mar Muerto}

El aprendiz, que parecía en este momento un campo de amapolas, estaba agobiado y se sentía sobrepasado por la dificultad de las enseñanzas.

El Maestro Gin y Seng le dijo:

-Joven-Campo-De-Amapolas-Rojas, lo estás haciendo muy bien. Me doy cuenta de tus grandes cualidades: capacidad de trabajo, dotes para la observación y escucha, y buena formación... Aunque ahora te parezca todo un mundo, verás que en unas semanas es sólo una colina, gracias a esas cualidades que percibo en ti.

Joven-Campo-De-Amapolas-Rojas se puso un poco más rojo. El Maestro Gin y Seng continuó:

-Debes olvidar el "no soy capaz" mental y emocional. Lo más maravilloso puede llegar sin enterarnos.

- ¿Me lo dice de verdad? -preguntó Joven-CampoDe-Amapolas-Rojas.

-Desde luego -dijo el Maestro, mientras pensaba: $<<$ El maestro debe dar en vez de quitar, elogiar en vez de castigar, pero con honestidad y sinceridad. Esa es la manera de alimentar la vida en respuesta a la primavera $>>$.

El Maestro Gin y Seng pensó que había descubierto la 'Ley del Mar de Tiberíades y del Mar Muerto'. Recordó que hay en el Cercano Oriente dos lagos alimentados por el mismo río que los une, el río Jordán, situados a unos kilómetros de distancia el uno del otro, pero con características asombrosamente distintas. Uno es el lago de Genesaret o mar de Tiberíades y el otro es el mar Muerto. El primero es azul, lleno de vida y de contrastes, de calma y de borrasca. En sus orillas se reflejan delicadamente las flores sencillas 
amarillas y rosas de sus bellísimas praderas. El mar Muerto es una laguna salitrosa y densa, donde no hay vida y queda estancada el agua que viene del río Jordán. ¿Qué es lo que hace tan diferentes a los dos lagos alimentados por el mismo río? Es sencillamente que el lago de Genesaret trasmite generosamente lo que recibe; su agua, una vez llegada allí, parte inmediatamente; mientras el agua del mar Muerto se estanca, se adormece. Cuánto más damos, más recibimos.
El Maestro Gin y Seng, entró en un estado como de meditación y pensó: <<El maestro debe actuar de acuerdo a los sentimientos de amor y compasión por el aprendiz. Esto incluye conocer lo que no hay que enseñar, por ser un material inadecuado, un momento inoportuno, o no estar preparado el aprendiz para recibirlo. La enseñanza debe hacerse sólo si puede beneficiar al aprendiz $>>$.

Y escribió en la pizarra: Es lo mismo dar y recibir, porque el universo fluye de esa manera. 